\title{
A TRINDADE POUCO SANTA DE RICHARD PEET
}

Luís MENDEs ${ }^{1}$

Uma das mais recentes obras de Richard Peet Unholy Trinity ${ }^{2}$ utiliza brilhantemente as ideias de poder, de interesse político, de hegemonia, de discurso e do poder da praticalidade, para fazer uma análise crítica de três instituições: o Fundo Monetário Internacional (FMI), o Banco Mundial e a Organização Mundial do Comércio (OMC). A tese do livro é a de que elas desempenham na actualidade papéis bastante diferentes dos previstos nos acordos que as criaram. Esta trindade "pouco santa" governa uma economia cuja ideologia neoliberal insiste ser melhor, se institucionalmente não governada.

Esta tese cruza, aliás, um dos maiores e recentes interesses de investigação de Richard Peet: a genealogia do neoliberalismo. Não se estranha, assim, que o livro nasça dos esforços empenhados de um grupo de alunos de diversos graus académicos da Clark University, em Worcester, Massachussets, onde Peet lecciona Geografia, há dezenas de anos, e onde dirige um dos movimentos de Geografia radical mais activos de todo o Mundo. A ideia foi fazer um estudo crítico das três poderosas instituições globais mencionadas, tendo como contexto ideológico a análise dos princípios do neoliberalismo. Faz-se uma abordagem histórica e geográfica, partindo da ideia de que as políticas actualmente seguidas por estas três instituições derivam de um considerável registo de experiências, retiradas, reafirmações e ainda de acumulação abrangente de poder e de influência. As três conseguiram obter posições de aparente concordância, ao assumir uma posição que combina rigidez institucional com fluidez de procedimentos. Ou, para colocar a questão de modo mais crítico, e com especial referência aos anos mais recentes, elas aprenderam que uma pequena volta e algumas confissões de falhanço parcial ("temos muito que aprender") desculpam muitos abusos no exercício do poder.

No capítulo 1 apresenta-se com alguma extensão uma teoria de hegemonia, num discurso que ajuda a compreender o enredo de poderes, interesses, instituições e ideologias, que se combinam para formar a política económica internacional. Desenvolvendo a noção de hegemonia de Gramsci, Peet argumenta que o poder na arena política consiste essencialmente em controlar o conceito predominante de "bom senso económico". Este é produzido por grupos de especialistas em importantes instituições e é protegido por uma aura de responsabilidade.

1 Investigador do Instituto de Geografia e Ordenamento do Território da Universidade de Lisboa. E-mail: luis.mendes@ceg.ul.pt

2 Peet R, et al. (2005), Unholy Trinity: the IMF, World Bank and WTO, London, Zed Books (Edição portuguesa, 2007, Uma Trindade Pouco Santa: o FMI, o Banco Mundial e a OMC, Cascais, Sururu). 
Sugere-se que, mais do que emergir dessas instituições a neutralidade científica, os seus discursos políticos geram, de facto, convicções político-económicas. Na verdade, estes grupos de instituições são agentes que, concretamente, levam a cabo a produção de prescrições de políticas económicas cientificamente legitimadas, por conta dos interesses do poder. A pesquisa da História e da Geografia, bem como das práticas correntes das três organizações de governação global, levada a cabo pela equipa coordenada por Peet, sugere que a política económica hegemónica é formada através de interacções entre três tipos de agentes institucionais - burocráticos, económicos e políticos - com dois outros conjuntos de instituições - académicas e meios de comunicação social - envolvidas de forma mais autónoma.

No capítulo 2 olha-se para as condições económicas e políticas que tornaram possível que a Conferência de Bretton Woods criasse o FMI e o Banco Mundial. Este capítulo aborda dois tipos de condições: as decorrentes da realidade política e económica, dominada pelo declínio do domínio geopolítico da Grã-Bretanha, as exigências da Grande Depressão e a ascensão dos Estados Unidos; e as condições de teoria económica, especialmente a quebra da santidade do paradigma clássico e neoclássico e a ascensão da emenda keynesiana. Estas duas grandes mudanças cruzaram-se na formação de uma espécie de clube global keynesiano, de que resultaram as instituições de Bretton Woods, concebidas para regularem as relações económicas internacionais, de modo a que o mundo nunca mais sofresse a ameaça de uma perturbação total. A moldura institucional da nova hegemonia global podia parecer ter resultado da consulta e discussão entre nações e Estados-membros iguais. A realidade histórica é diferente. Através de um exame detalhado das condições, debates, preparações e manobras ligadas à Conferência de Bretton Woods de 1944, a posição dos autores é a de que esta foi uma ocasião para a formalização do domínio norte-americano e britânico num acordo monetário internacional, complementado com instituições que o aplicaram. De todas as "grandes potências", os EUA foram os mais renitentes a serem regrados por qualquer coisa que se parecesse com uma instituição independente.

Deste modo, o capítulo descreve com detalhe o modo como os EUA vieram dominar a agenda económica internacional do pós-guerra. Tal como se demonstra mais à frente, $\mathrm{o}$ FMI não foi formado como uma instituição democrática, pois não revela qualquer sentido de igualdade entre os países. É, antes de mais, uma invenção norte-americana, com a colaboração britânica, conscientemente desenhada para promover uma determinada perspectiva sobre o desenvolvimento das relações económicas globais. Foi sedeado em Washington, para ser colocado dentro do sistema de elaboração de políticas, dominado pelo Tesouro norte-americano. O sistema de votos foi deliberadamente desenhado para permitir que a vontade norte-americana prevalecesse, e para evitar que as políticas que não fossem do interesse norte-americano fossem adoptadas, sem sequer serem discutidas. Com um terço de todas as quotas no início, os EUA asseguraram para si próprios um poder de veto efectivo sobre os processos de decisão futuros. Demonstra-se, através de uma descrição pormenorizada, como os EUA dominaram a conferência de Bretton Woods e a dirigiram de acordo com os seus próprios interesses. Os EUA emergiram dela como uma potência mundial hegemónica sem rival, dominando a economia global no quarto de século que se seguiu. Neste capítulo defende-se que o FMI e o Banco Mundial foram criados como instituições dominadas pelos EUA, como disfarces colectivistas da política económica internacional do próprio país. Alguns diriam mesmo que surgiram como braços de uma nova ordem mundial, caracterizada por um imperialismo mais subtil e eficaz, capa de um capitalismo desorganizado, maduro e/ou tardio. 
O capítulo 3 reconstrói a história do FMI, a mais poderosa das duas instituições de Bretton Woods. Originalmente, o FMI agia no âmbito das taxas de câmbio e de empréstimos de apoio à balança de pagamentos, aspectos importantes e relativamente incontroversos da regulação financeira internacional. Embora a sua declaração de missão permaneça essencialmente igual, o FMI sofre subsequentemente grandes mudanças, incluindo alguns aparentes reveses da fortuna que, paradoxalmente, resultaram numa acumulação geral de poder e influência. Assim, a instituição passou a adoptar, em meados da década de 1970, uma posição mais intervencionista, ao abrigo da qual os empréstimos eram concedidos sob condições de maior austeridade, sobretudo quando dirigidos aos países do Terceiro Mundo. O seu papel deixou de ser o de um meio de colaboração relativamente a taxas de câmbio e pagamentos, sobretudo entre os países industrializados, para ser uma forma de o Primeiro Mundo controlar o Terceiro Mundo no que toca a políticas económicas. O poder do FMI deriva do controlo directo e indirecto que mantém sobre a concessão de empréstimos a governos que estejam a sofrer uma crise na balança de pagamentos e com dificuldades em pagar os juros e o capital das dívidas externas. O poder é exercido através das condições especificadas nos programas de estabilização e ajustamento, que são impostas na concessão de empréstimos desesperadamente necessários. As medidas de austeridade do Fundo surgem como necessárias pois encontram-se acopladas a programas de ajustamento, inevitavelmente vistos como factor compulsório para estabelecer a capacidade dos países devedores de assegurar o serviço da dívida.

A "condicionalidade" dos empréstimos a que Peet se refere baseava-se numa concepção ideológica muito particular acerca do modo como os países alcançam o crescimento económico. Esta concepção neoliberal, por sua vez, foi formulada por políticos e burocratas de direita que agiam através do Tesouro norte-americano durante uma série de administrações republicanas nos anos 1970 e 80 . Os resultados da condicionalidade neoliberal, em conjunto com outras iniciativas políticas relacionadas, tal como a liberalização da conta de capital, foram desastrosos para os trabalhadores e não só. $\mathrm{Na}$ actualidade, as políticas do FMI afectam directamente as economias de mais de 180 países e influenciam, por vezes drasticamente e com frequência de forma desastrosa, as vidas da vasta maioria da população mundial.

As manifestações de descontentamento, que inicialmente eram feitas sob forma de distúrbios originados por falta de alimentos, tornam-se protestos populares massivos por parte de trabalhadores e estudantes, entre outros activistas de organizações esquerdistas, empresariais e trabalhistas, sempre que o Fundo tenta reunir. Emergem acções colectivas em larga escala, incluindo manifestações políticas, greves gerais e tumultos, que são animadas por agravos causados pelas políticas estatais de liberalização económica, implementadas em resposta à crise da dívida e a reforma do mercado, concedidas e implementadas pelo FMI. O cancelamento de subsídios a bens básicos, de acordo com as exigências do FMI, figuram também como motivo de tumultos, não só devido à ameaça da fome, mas porque o significado acordado, ou a historicidade daquilo que constituía progresso social, fora quebrado entrando em vigor uma nova historicidade, criada pelo FMI, que proibia os Estados de cumprir a sua parte do contrato/pacto social. Em resposta, o FMI pôs uma capa de preocupação sobre a sua base de austeridade, sob forma de perdão de dívida, programas anti pobreza e de participação pública. As análises críticas sugerem que estas são mais efeito do que substância.

O capítulo 4 descreve a trágica perda do potencial inerente do que se tornou um banco de desenvolvimento global. O papel limitado inicial do Banco Mundial tornava-o num actor 
secundário na reconstrução de uma Europa devastada pela guerra. Na década de 1950, a atenção da instituição virou-se para a concessão de empréstimos para projectos nos países mais ricos do Terceiro Mundo. Mas nas décadas de 1960 e 1970, o alívio da pobreza e o desenvolvimento rural, com a resolução de necessidades básicas, tornaram-se nas principais preocupações do Banco. Embora isto soasse melhor na retórica de desenvolvimento do que na prática da política, a verdadeira tragédia do Banco Mundial só chegou no final da década de 1970.

Confrontado com uma verdadeira viragem à direita nas condições políticas, o Banco viu-se envolvido num ajustamento estrutural com recurso à utilização de políticas neoliberais, cada vez mais em concertação com o FMI, fixando programas de estabilização (concessão de empréstimos de curto prazo para ajustamento). O argumento era o de que as novas condições enfrentadas pelos países em desenvolvimento - degradação dos termos de troca e crescentes dívidas externas - os forçava a reconsiderar a forma de "ajustar" os seus padrões de desenvolvimento e estruturas económicas. Esta mudança de atitude a favor de políticas mais intervencionistas por parte do Banco, relativamente ao país mutuário, fez com que as preocupações com a erradicação da pobreza cedessem posição às novas forças motoras da política macroeconómica, estabilização e ajustamento na balança de pagamentos, tudo compreendido no âmbito de uma doutrina mais à direita, mediante os limites rígidos da intervenção governamental e às virtudes dos mercados livres flexíveis e auto-ajustáveis.

$\mathrm{O}$ ajustamento estrutural tornou-se no principal meio de transportar estas conviçcões políticas para a prática económica. Neste sentido, a condicionalidade é a ligação entre a versão do Banco das convicções neoclássicas, orientadas para a direcção certa, através de uma injecção de neoliberalismo durante as administrações Reagan e Bush nos EUA, e os compromissos feitos pelos países mutuários de cumprirem condições específicas, estipuladas pela instituição mutuante, como a base para a concessão de um empréstimo, ou para permitir levantamentos subsequentes de dinheiro de empréstimos previamente atribuídos.

O capítulo 5 apresenta uma breve história crítica das condições políticas, económicas e ideológicas que estiveram na base da formação do Acordo Geral sobre Tarifas e Comércio (GATT). Faz-se um resumo das várias rondas de reuniões subsequentes do GATT, que culminaram na Ronda do Uruguai, assinada numa reunião ministerial em Marraquexe, em 1994, que expandiu largamente o escopo dos acordos comerciais e deu origem à OMC. Criada a 1 de Janeiro de 1995, a OMC é uma versão mais formal e institucionalizada do GATT, ratificado por 23 governos em 1947. O sistema GATT/OMC regula o comércio internacional de bens e serviços, usando um sistema de objectivos e normas apresentados nos estatutos aprovados pelos governos membros.

A OMC opera no âmbito de um discurso que, embora tenha conhecido alterações de ênfase ao longo do tempo, advogou firmemente a liberalização do comércio, isto é, a libertação dos movimentos internacionais de mercadorias e de serviços de restrições governamentais. Defende-se que libertar o comércio de tarifas e outras barreiras governamentais, permitindo assim a concorrência e o livre funcionamento internacional dos mercados, conduz a um crescimento económico mais rápido que beneficia todos. A OMC afirma que o seu objectivo é o "comércio justo", sem discriminação, assegurando que as condições para o comércio sejam estáveis, previsíveis e transparentes. Por outras palavras, a interpretação da OMC de "justiça" é limitada às condições exactas nas quais ocorre o comércio livre - que os países cumpram as regras, actuem de forma transparente, etc. Com esta restrição rigorosa, o comércio pode funcionar "justamente" num sistema que favorece de um modo mais geral alguns interesses, embora prejudique outros. 
A OMC não pratica uma neutralidade organizacional e burocrática. Como organização, tem um compromisso total com uma única posição ideológica, bem definida, explicada e cuidadosamente defendida. $\mathrm{Na}$ verdade, os países são pressionados a aderir ao processo que resulta num único objectivo final, a economia "aberta" e "liberalizada", que supostamente assenta no modelo dos EUA; na realidade assenta num modelo neoliberal idealizado de direita. Este trabalho de Peet insiste em como a liberalização do comércio é um dos aspectos orientadores do regime económico do pós-guerra que conduziu ao neoliberalismo global, baseado nos princípios de liberalização e igualdade de acesso ao mercado, envolvendo essencialmente a redução de tarifas e a desregulamentação comercial, na convicção de que a intervenção estatal perturba o funcionamento naturalmente eficiente do mercado.

O capítulo analisa em pormenor a estrutura organizacional da OMC enquanto administradora daquilo que se tornou num conjunto complexo de procedimentos institucionais, que regulam o comércio internacional, cativo doravante aos princípios neoliberais. Sujeita-se, assim, a OMC a um conjunto de interrogações críticas nomeadamente: o seu mecanismo de revisão da política comercial, examinado como um instrumento de disciplina neoliberal; o seu registo de resolução de conflitos procurando que comércio livre tenha preferência, de forma consistente, sobre a regulação ambiental e de defesa dos direitos dos trabalhadores; as suas atitudes relativamente ao trabalho na detecção de favorecimento de classes. As políticas comerciais e de crescimento da OMC podem ser responsabilizadas pela destruição ambiental produzida por níveis cada vez mais elevados de produção e de consumo. Isto acontece particularmente quando o aumento da competitividade internacional, favorecida pelo sistema de comércio liberalizado da OMC, reduz a capacidade política e económica dos Estados para regular a produção a nível ambiental. Por outro lado, a OMC não tem políticas orientadas para os trabalhadores, apesar do vago compromisso de "observar" normas laborais essenciais, ou debater os direitos dos trabalhadores e as normas de emprego. Embora consistentemente relacionado com os rendimentos, o consumo e os estilos de vida, na retórica da OMC, o comércio está isolado do emprego e das condições laborais. Isto é coerente com uma perspectiva neoliberal que respeita as pessoas como consumidores, mas lhes nega os seus direitos como trabalhadores. $\mathrm{O}$ capítulo presta também atenção aos vários tipos de oposição à OMC, com ênfase na erupção de protestos em Seattle, em 1999. Enquanto o GATT era relativamente incontestado, a OMC, como grande proponente de ideias neoliberais, está no centro da controvérsia sobre a direcção que a globalização tomou. Conclui-se com uma avaliação global crítica da OMC.

O sexto e último capítulo revê os conceitos de hegemonia, poder e praticabilidade, com os quais se ocupou também o capítulo introdutório. Reexamina-se, de modo crítico, a expressão "Consenso de Washington", como descrição das políticas e poderes na base das recentes tendências da governação global. Por detrás dos interesses políticos representados pelas burocracias de Washington, Peet observa um poder mais forte: o das grandes empresas, especialmente dos bancos de investimento de Nova Iorque. Conclui-se que da Aliança Washington-Wall Street resulta uma política económica global, levada a cabo por uma instituição de governação cada vez mais coordenada. Esta aliança estabeleceu, protegeu e reforçou um regime político neoliberal que serviu para desregular a economia mundial (em termos de intervenção dos Estados nacionais), abrindo às empresas, e particularmente às norte-americanas, o caminho para o comércio de bens industrializados sem interferência e para o movimento de valores imobilizados até então pelas fronteiras nacionais. As condições de crédito do FMI e do Banco Mundial têm coincidido com os requisitos de adesão à 
OMC e enfraquecem insidiosamente a capacidade dos Estados regularem as próprias economias, promoverem as indústrias domésticas e protegerem o interesse público de curto e longo prazo. Ao mesmo tempo, os efeitos combinados da sua promoção conjunta da liberalização comercial têm possibilitado de forma crescente aos agentes do sector privado, nomeadamente às empresas multinacionais, gozar de liberdades sem precedentes no processo de aprofundamento e expansão da globalização da economia. 